Electronic version of an article published as [Nuclear Tracks and Radiation Measurements, 1984, vol.8, No.1-4, p. 17-20] [doi:10.1016/0735-245X(84)90047-4] (c) [copyright Elsevier] 


\section{A STUDY OF ETCHING CONDITIONS AND RESOLUTION POWER OF PLASTIC DETECTOR CR-39}

\section{Domingo, M. Ortega, F. Fernandez, A. Vidal-Quadras,} J.L. Font, C. Baixeras and M. Casas.

Laboratorio de FIsica Corpuscular. Departamento de FIsica Fundamental. Universidad Autónoma de Barcelona. Bellaterra (Barcelona). Spain.

\section{ABSTRACT}

Two Pershore Stacks ( $32 \mathrm{~h}$ cure cycle and $1 \%$ DOP and $96 \mathrm{~h}$ cure cycle and no additive) have been exposed to the Berkeley Bevalac Argon beam at $285 \mathrm{MeV} / \mathrm{nuc}$ and $425 \mathrm{MeV} / \mathrm{nuc}$, respectively. 0ptimum etching conditions have been found to be $70^{\circ} \mathrm{C}$ temperature and $18 \mathrm{~h}$ etching time in $6.25 \mathrm{~N}$ OHNa aquaeous solution, corresponding to a mean bulk etch rate $V_{B}=(1.37 \pm 0.09) \mu \mathrm{m} / \mathrm{h}$. The charge and mass resolution power of the detector has been evaluated as $\Delta \mathrm{Z} \simeq 0.3 \in$ and $\triangle \mathrm{A} \simeq 2 \mathrm{a} . \mathrm{m}$. u. .

\section{KEYWORDS}

CR-39, Argon, charge and mass resolution power.

\section{INTRODUCTION}

Efficient isotope resolution of heavy ions is an old aspiration of the SSNTD cosmic ray rese arch. Our laboratory has devoted a considerable effort to this problem using $\mathrm{CN}$ and Lexan (OrEega, 80; Gonzalo, 82; Vidal-Quadras,82, 83). Much hope was deposited in this respect on CR-39 since its discovery (Cartwright 78). In this paper an evaluation of charge and mass resolution power of CR-39 for Argon is presented and compared to more favourable results in the literature, which are critically discussed.

\section{EXPERIMENTAI METHOD}

Two stacks of CR-39 were exposed to an ${ }^{40} \mathrm{Ar}$ beam of $285 \mathrm{MeV} / \mathrm{nuc}$ and $425 \mathrm{MeV} /$ nuc, respectively. The first stack (A) consisted of 76 plates, each of size $(50 \times 40 \times 0.6) \mathrm{mm}^{3}$, and the second (B) of 108 plates, $(85 \times 40 \times 0.6) \mathrm{mm}^{3}$. Both stacks were supplied by Pershore Motidirg Ltd. Stack A was manuiactured according to a $32 \mathrm{~h}$ cycle (Adams,82) and had a $1 \%$ of Dop adjitive (Tarlé, 81 ; Price, 82). Stack $B$ was pure CR-39 cured according to a 96 h cure cycle (Fowler, 80). Etching of stack $A$ was carried out in $6.25 \mathrm{~N}$ OHNa aqueous solution with $0.05 \%$ Dowfax surfactant, at $(40.0 \pm 0.3)^{\circ} \mathrm{C}$ for $144 \mathrm{~h}$ and 20 of the revealed tracks in a scanned area of $6 \mathrm{~cm}^{2}$, all. stopping in plate 71, were measured with a total of 748 experimental (L,R) points. Bulk etch rate was determined for each plate separately by the direct measurement of its thickness and a great dispersion was observed both in surface and from plate to plate with a mean value $V_{B}=(0.080$ $\pm 0.008) \mu \mathrm{m} / \mathrm{h}$, with $11 \mu \mathrm{m}$ of removed thickness from each surface. The experimental (L,R) points can be seen in Fig. 1, where the low sensitivity of the material can be appreciated. Between $Z / B \simeq 30$ and $Z / B \simeq 90$, etch rate is $f l a t$ and equal to $V_{T} \simeq 0.15-0.20 \mu \mathrm{m} / \mathrm{h}$. Only in plate 70 the$\mathrm{re}$ is some steepness in the L-R curve, showing a response to increasing ionization. Similar conclusions can be reached when examining the behaviour of the ratio $V_{T} / V_{B}$.

Etching of stack B was done at $(70.0 \pm 0.1)^{\circ} \mathrm{C}$ during $18 \mathrm{~h}$, also in 6.25 OHNa solution, conditions that proved to be optimal. A test was perfomed at $55^{\circ} \mathrm{C}$ and also severai etching times were tried with $4 \mathrm{~h}$ intervals. Total number of measured tracks in a scanned area of $11 \mathrm{~cm}$ was 60 , 30 stopping in plates $92-94$ and 30 in plates 104-108, in order to introduce fragmentation ions 
in the spectrum. Total number of experimental ( $L, R$ ) points was 870 . Bulk etch rate was much more uniform in surface and from plate to plate than in stack $A$ and its mean value was $V_{B}=(1.37$ $\pm 0.08) \mu \mathrm{m} / \mathrm{h}$, with $25 \mu \mathrm{m}$ of removed thickness. The bulk etch rate for $55^{\circ} \mathrm{C}$ was $\cup_{\overline{5}}=(0.511 \pm 0.05)$ $\mu \mathrm{m} / \mathrm{h}$, a third of that at $70^{\circ} \mathrm{C}$. The experimental ( $\mathrm{L}, \mathrm{R}$ ) points for stack $\mathrm{B}$ can be seen in Fig. 2 , where the behaviour of the material is much nicer than that in Fig. 1 . The steepness of the L-R curve starts to manifest clearly at $Z / B \simeq 45$.

\section{DETERMINATION OF CHARGE AND MASS RESOLUTION POWER}

The information contained in each track has been reduced to a single parameter, its mean residual range $\bar{R}$, and this parameter allows tocalibrate the detector obtaining a charge and mass $\overline{\mathrm{R}}$-scale for the region of interest (Siegmon, 78; Gonzalo, 82; Vidal-Quadras, 83). The histogram of $\bar{R}$-values for stack B is shown in Fig. 3, as well as the superimposed charge scale. Tracks in the peak have been considered to be ${ }^{40} \mathrm{Ar}$ and used as calibration points. The theoretical L-R curves for different charges can be seen in Fig. 2. The fitted values for parameters $g$ and $h$ in the interval $3 \times 10^{3} \mathrm{MeV} \cdot \mathrm{cm}^{2} / \mathrm{g} \widetilde{<} \mathrm{REL}_{200} \approx 6 \times 10^{3} \mathrm{MeV} \cdot \mathrm{cm}^{2} / \mathrm{g}$ for the relation $\mathrm{V}_{\mathrm{T}}=\mathrm{gREL}_{200}$ are printed on the L-R plot. Threshold for restricted energy loss REL has been chosen $\omega_{0}=200$ eV (Henshaw, 82). The experimental uncertainty in the determination of $\bar{R}$ for each $t r a c k$ is $\Delta \bar{R} \simeq$ $100 \mu \mathrm{m}$ and the comparison between the mass $\bar{R}-$ scale and the uncertainty can be seen in Fig. 4 . Charge uncertainty turns to be $\Delta Z \simeq 0.3 \mathrm{e}$ and mass uncertainty $\Delta A \simeq 2 \mathrm{a} \cdot \mathrm{m} . \mathrm{u}$.

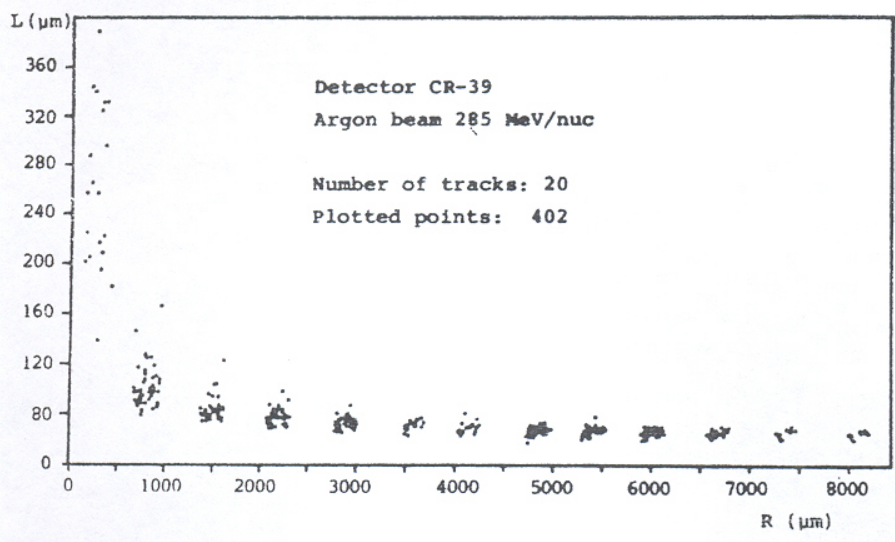

Fig. 1. Experimental L-R points for stack A. Etch rate is almost flat for a very wide REL interval.

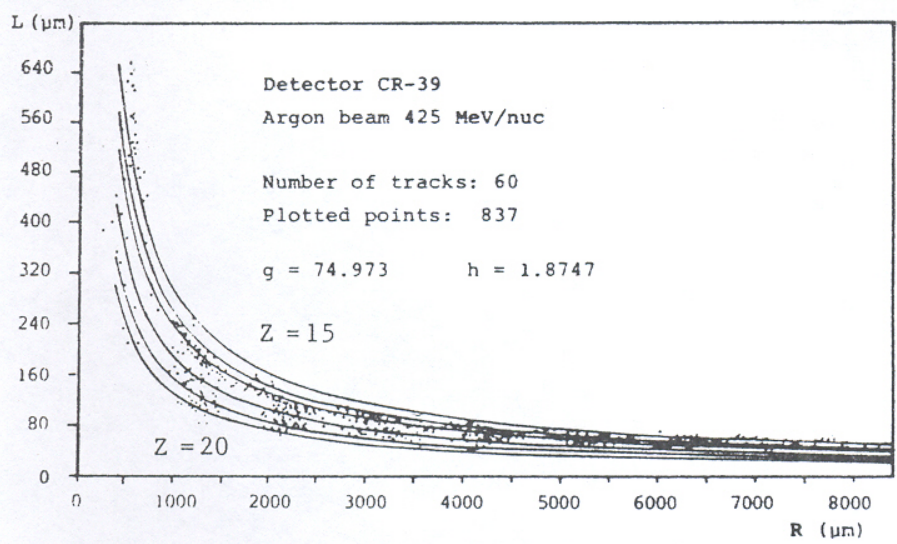

Fig. 2. Experimental L-R points for stack $B$ and theoretical L-R curves for different charges. Steepness of etch rate vs. REL is satisfactory.

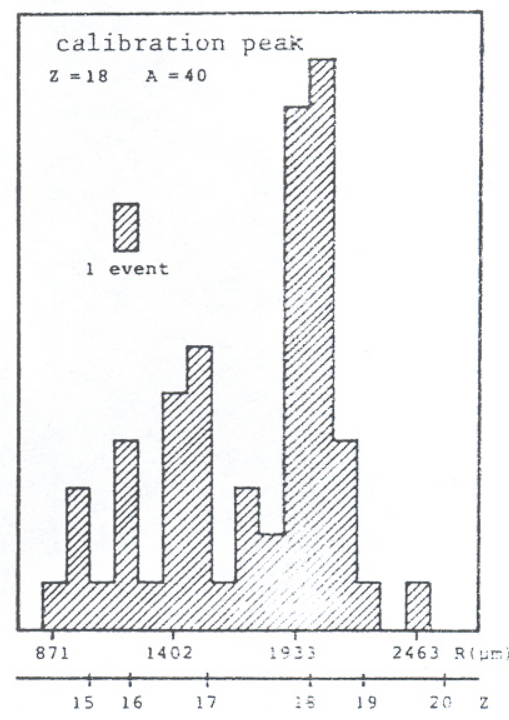

Fig. 3. Histogram of experimental $\bar{R}$-values and superimposed charge scale. 


\section{DISCUSSION OF RESULTS}

The chosen optimal etching conditions agree with those recommended by other authors (Somogy, 82; Green, 82). No saturation of response of the type reported by Hayashi (82) for Fe ions is observed. The very low sensitivity of the stack A to increasing REL over such a wide interval indicates a problem in the material. The same unsatisfactory results for this particular batch have been observed in other Laboratories (0'Sullivan, 83). The reproducibility of CR-39 response is not yet a closed question and uncontrolable lack of reproducibility and homogeneity over large stacks, so essential for cosmic ray work, seems far to be overcome (Thompson, 80; Somogy, 82). The value of $h$ for the semiempirical relation $V_{T}=g R_{20} L_{2}$ agrees with that reported by Henshaw (81) for a similar REL interval. Charge resolution $\Delta z \simeq 0.3$ is consistent with previous measurements in analogous conditions (Thompson, 82), but worse than some other more optimistic predictions (Cartwright, 78) or determinations (Tarlé, 81). In this sense, it must be emphasized the difference between working with a single foil and wedge energy dispersion or with a large stack. As for mass resolution $\Delta \mathrm{A} \simeq 2 \mathrm{a} . \mathrm{m} . \mathrm{u}$., it is very poor compared to initial expectancies (Cartwright, 78; Cassou, 78) and extremely dissapointing compared to Hayashi's promising $\Delta A=0.4 \mathrm{a} \cdot \mathrm{m} . \mathrm{u}$. (Hayashi, 82). In order to clarify this discrepance we have applied Hayashi's method to our Argon measured tracks in stack B. The mean standard deviation of cone lengths around the fitting ${ }^{40} \mathrm{Ar}$ curve is $3 \%$, the mean mass deviation is $\overline{\mathrm{C}}_{\mathrm{M}}=(1.1 \pm 0.5) \cdot \mathrm{a} . \mathrm{m} \cdot \mathrm{u}$. , the average of reduced cone number is $\bar{N}=2.50 \pm 0.31$ and mass resolution turns finally to be $\Delta \mathrm{A}=\bar{\sigma}_{\mathrm{M}} / \sqrt{\mathrm{N}}=(0.68 \pm 0.31)$ a.m.u. It is clear that a purely statistical handling of data with no reference to experimental errors in the measurement of cone length and residual range leads to "wishful" estimations of resolution which are unhappily not realistic.

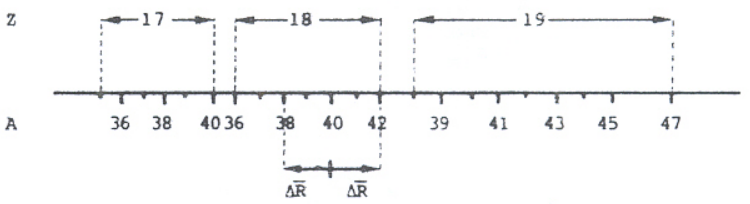

Fig. 4. Comparison between the mass $\overline{\mathrm{R}}$-scale and the experimental uncertainty $\Delta \bar{R}$.

$\Delta A \simeq 2 \mathrm{a} \cdot \mathrm{m} \cdot \mathrm{u}$.

\section{ACKNOWLEDGMENTS}

The authors want to thank financial support from the Spanish Comision Nacional de Investigacion del Espacio (CONIE) and from the Comisió Interdepartamental de Recerca y Tecnologia de la Generalitat de Catalunya (CIRIT). They also want to express their gratitude to Drs. D. O'Sullivan and A. Thompson from the Dublin Institute for Advanced Study and to Dr. M Debeauvais from the C.R.N. of Strasbourg for valuable help and enlightening discussions.

\section{REFERENCES}

Adams, J.H. (1982). A curing cycle for detector quality CR-39. Muct. Trasks, Supp. 3, 145-148. Cartwright, B.G., Shirk, E.K. and Price, P.B. (1978). A nuclear track recording polymer of unique sensitivity and resolution. Nucl. Inet. $6 . ; 153,457-460$.

Cassou, R.M. and Benton, E.V. (1978). Properties and applications of CR-39 polimeric nuclear track detector. Nucl. Tracks, 2, 173-179.

Fowler, P.H., Clapham, V.H., Henshaw, D.L., O'Sullivan, D. and Thompson, A. (1980). The effect of the temperature-time cycles in the polimerisation of CR-39 on the uniformity of track response. Nucl. Tracks, Supp. 2, 437-442.

Gonzalo, M., Vidal-Quadras, A., Ortega, M., Fernández, F., Baixeras, C., Casas, M., Sequeiros, $\mathrm{J}$. and Medina, J. (1982). Sensitivity of Lexan polycarbonate to mass differences in the Iron peak. Nucl. Tracks, supp. 3, 291-294. 
Green, P.F., Ramli, A.G., Hashemi-Nazhad, S.R., Al-Najjar, S.A.R., Doi, C.M., Abu-Jarad, F. Bull, R.K. and Durrani, S.A. (1982). On the optimisation of etching conditions for CR-39 and other plastic track detectors. Wuch. Traoke, Supp. 3, 179-182.

Hayashi, T., Hamasaki, R. and Doke, T. (1982). Mass resolution for Iron isotopes in the plastic CR-39. Nucl. Tracks, 6, 1-7.

Henshaw, D.L., Griffiths, N., Landen, D.A.I. and Benton, E.V. (1981). A method of producing thin CR-39 plastic nuclear track detectors and their application in nuclear science and technology. Nucl. Inst. and weth., 180, 65-77.

Henshaw, D.L., Amin, S., Clapham, V.H., Fowler, P.H., webster, D.J., Thompson, A. and O'Sullivan, D. (1982). The form of the CR-39 response curve and its effect on particle resolution and areas of application. Nucl. Tracks, Supp. 3, 115-118.

Ortega, M., Vidal-Quadras, A., Fernández, F., Bä́xeras, C., Casas, M., Gonzalo, M., Medina, J., and Sequeiros, J. (1980). A charge and mass discrimination method in Lexan polycarbonate. Nucl. Tracks, Supp. 2 , 1041-1046.

Price, P.B. and O'Sullivan, D. (1982). Improving the etching properties and tailoring the response of CR-39 plastic track detectors with dopants. Wuci. Trocks, Supp. 3, 929-932.

Siegmon, G., Bartholoma, K. and Enge, W. (1978). Composition of Fe-isotopes in cosmic rays. Nucl. Tracks, Supp. 1, 1059-1068.

Somogy, G. (1982). Status of development in the field of CR-39 Track Detectors. Wucl. Tracks, Supp. $3,101-113$.

O'Sullivān, D. (1983). Private communication.

Tarlé, G., Ahlen, S.P. and Price, P.B. (1981). Energy straggling eliminated as a limitation to charge resolution of transmision detectors. Watwe, 293, 556-558.

Thompson, A., O'Sullivan, D. and O'Ceallaigh, C. (1980). Development studies of CR-39 for cosmic ray work. Wuct. Tracks, Supp. 2 , 453-458.

Thompson, A., O'Sullivan, D., Henshaw, D.L., Amin, S., Clapham, V.M., Fowler, P.H. and Webster, D.J. (1982). An improved CR-39 track detector for cosmic ray applications. Nucl. Tracks, Supp. 3 , 149-153.

Vidal-Quadras, A., Ortega, M., Fernández, E., Font, J.L., Casas, M., Baixeras, C. and Gonzalo, M. (1983). Heavy ion isotope resolution with polymer detectors. Wucl. Inst. and Meth. (to be published).

Vidal-Quadras, A., Fernändez, F., Gonzalo, M., Ortega, M., Baixeras, C. and Casas, M. (1982). Sensitivity of cellulose Nitrate to mass differences in the low 2 region. Nuez. Tracks, Supp. 3, $257-260$. 